Koch, Andrew M. "What is Still Critical in the Work of Jürgen Habermas" Politics and Policy, 29 (1) 69-89. March 2001. Wiley-Blackwell (ISSN: 1555-5623) DOI: 10.1111/j.1747-1346.2001.tb00584.x Version of record at: http://www3.interscience.wiley.com/

\title{
What is Still Critical in the Work of Jürgen Habermas?
}

\author{
Andrew M. Koch
}

\begin{abstract}
This paper will present a strategic reading of Habermas's project since the publishing of his "Legitimation Crisis." We examine his consensus theory of truth, the assumption of mutually acceptable outcomes in political discourse, and the role of law in bringing about social solidarity. We argue that Habermas has made several questionable assumptions while constructing this project that leave him open to criticism. We suggest that in his desire to preserve the Enlightenment, Habermas has ignored the power dimension of political life, leading him in a very "uncritical" direction.
\end{abstract}

\section{ARTICLE}

\section{Introduction}

In his recent work, Between Facts and Norms, Jürgen Habermas denounces sociology for being overly critical and perpetrating a "disillusioning, if not downright cynical, view of the political process."(Habermas 1996, 329.) Such a condemnation appears curious, as Habermas has emerged from one of the more critical traditions within 
the discipline of sociology. However, for the last twenty years Habermas has been moving away from the first generation of Frankfurt School scholars.

After the publication of the Legitimation Crisis Habermas claims to have undergone a change in his thinking. As Habermas describes it, he used to think the problems of late capitalism were steering problems. Since that time, however, Habermas has come to the position that the problems of contemporary industrial society are normative in nature.(Habermas 1996, 333.)

Habermas makes it clear in numerous places that he views society as having lost its normative path. One of the best examples of this view can be found at the end of "The Unity of Reason in the Diversity of its Voices." Here, Habermas speaks of how normative discourse has given way to "contextualism." The problem, as Habermas describes it, is that contextualism takes what has traditionally remained at the margin of discourse and brought it to the center.(Habermas 1992, 140.) Even when reading a fictional detective story he claims to have been struck by the normative chaos of contextualism. The place of perpetrator and victim have been confused.(Habermas 1992, 140.)

Given his epistemological assumption that no metaphysical support can be provided for a universal ethical system, Habermas must confront a problem. If the contemporary crisis is normative, what kind of ethical system can be developed that satisfies the requirements for universality while also providing a mechanism for validation within a non-ontological and non-metaphysical framework?

Habermas seeks a universal ethical foundation. He bemoans the fact that universalism has come to be treated as an enemy of the individual just as the "unity of 
reason" has come to be painted as a form of repression.(Habermas 1992, 140.) Habermas claims that even a diverse, decentered society needs some reference point. This is provided by a projected unity, as presented in the idea of a common will.(Habermas 1992, 141.)

Habermas has attempted to strengthen the normative component of modernism with his discourse ethic. This strategy is designed to "deontologize" traditional modernist defenses of democratic practice rooted in metaphysics and the "philosophy of consciousness." Habermas seeks to accomplish this goal by externalizing the foundations of normativity, placing them within the structure of discourse itself. This normative turn forces Habermas back in the direction of Kant. In order to validate his commitment to Enlightenment values such as democracy, equality, humanism, and progress, Habermas has had to reject all skeptical and relativistic theories of knowledge and ethics. As a result of this position Habermas has rejected the epistemological relativism of the postmoderns, an epistemological paradigm that asserts all claims to social truth are reflective of historical conditions and power relations. Further, he has denounced the late modern subjectivism presented by Weber, in which Weber claims that all meaning in the world reflects subjective opinion. (Habermas 1984, 14.) Even the critique of instrumental reason offered by Horkheimer and Adorno, as the means-ends calculation associated with the promotion of capitalism, is insufficient for his defense of modernity. For that Habermas requires a formalized ethic of communication. (Habermas 1984, 383-386.)

This work will present a strategic reading of Habermas's project since the Legitimation Crisis. Critical works on Habermas abound. (Fleming 1996, Foster 1999, Whitton 1992, Horowitz 1998, Kaufman 1999) The goal of this essay is the 
representation of Habermas's writings as a series of problems to be solved. Through this type of reading it will be argued that Habermas's project fails on several fronts. First, there are real difficulties with the conception of truth that Habermas establishes in order to operationalize his discourse ethics. Secondly, Habermas has deontologized the subject by substituting an uncritical teleology which contains the premises of modernity. This modernist teleology stands in for the lost construct of subjectivity in his deontologized philosophy. In the end, therefore, Habermas is unsuccessful in his attempt to move beyond the choice between Hegel and Kant. This problem manifests itself politically, as Habermas can describe a democratic process but cannot offer a non-metaphysical explanation of why it should be defended.

Finally, this paper will claim that the movement toward language philosophy in Habermas's work has narrowed, if not eliminated, the liberating potential of discourse. The liberating possibilities within Freud have given way to the syntactical structures of language. Habermas has abandoned the critique of instrumentalism started by Weber and Lukacs and carried on by Adorno and Horkheimer. In its place, is an uncritical stand toward modernity, undercutting the work of the first generation of Frankfurt School scholars. Rather than offering a means to resist the instrumentalization of the lifeworld, Habermas actually extends it by instrumentalizing discourse itself. This is reflected in his latest work, where we get a defense of stabilizing possibilities of democratic practice rather than an expression of its liberating potential.

\section{Philosophy, Truth, and Reason}


Habermas proceeds from the premise that consensus on normative questions can be found. This can occur only when discourse takes place within a pragmatically justified set of rules for argumentation. His task is to legitimate such a project.

The problems to be addressed can be broken up into three sub-projects that give rise to Habermas's three major concerns of the last ten years. The first problem involves creating a method for validating truth that is not grounded in metaphysical assumptions. (Postmetaphysical Thinking). Next, a foundation for the establishment of a universalist ethic must be constructed that does not emerge from metaphysics (Moral Consciousness and Communicative Action). And finally, Habermas moves into the discussion of the implications of this for politics, the law, and legislation in his latest work. (Between Facts and Norms) During this time Habermas has had to confront his critics, particularly the structuralists and the poststructuralists, and contextualize his own transformation (The Philosophical Discourse of Modernity and Justification and Application).

This schemetization might appear a bit too simplistic, and it is. Clearly the works overlap and reinforce one another. However, an understanding of how the works fit together helps to clarify the role each work plays in an overall project.

\section{A. The Problem of Metaphysics}

The problems that Habermas needs to confront with his attempt to move beyond metaphysics cannot be separated from his overall defense of the Enlightenment project. In the British Empiricist tradition the project of validating truth claims had been intertwined with the project of defining the parameters of subjective experience. This took the form of a connection between sense impressions and the emergence of the idea 
in the individual.(Locke, 1961 and Hume, 1962.) The problem with this strategy of validation is that projecting from individual subjective experience to a universal condition requires a metaphysical jump. As Hume recognized, one must always remain skeptical of such an imposition by the mind.

A different metaphysical problem emerges within Kant's modernism. For Kant, two metaphysical assumptions initiate the project. The first is the universal character of reason, which is attributed to human nature as a whole. The second assumption concerns the underpinning of all morality, the assumption of freedom of the will. Even while admitting he cannot prove the latter, Kant will state emphatically that the autonomy of the will is the supreme principle of morality.(Kant 1971, 187.) Linked to the assumption of freedom, the categorical imperative is a logical deduction based on the universalization of the premises. As Kant admitted, what emerges is a metaphysical doctrine, based on the premise of human free will.(Kant 1965, 13-16.)

Habermas's challenge is to produce a non-metaphysical form of validation that is not embedded in the philosophy of the consciousness. Such a form of validation must be able to serve as a foundation for universality, and thus provide support for humanism, democratic political practice, and a plurality of forms of living within the lifeworld. To this end, Habermas accepts the universality of reason, albeit in a reformulated fashion. Habermas also reformulates the categorical imperative. In the postmetaphysical framework, it is a set of conditions necessary for normative validity without the assumption of free will embedded in a philosophy of consciousness.(Habermas 1990, 78.)

The problem of producing a non-metaphysical form of validation is solved using the structure of communication. The validating mechanism for truth claims is then 
outside both ontological assumptions about human nature and subjective modes of validation. Communication through language assumes that there is a common objective world that all of the participants are discussing.(Habermas 1992, 138.) It further assumes that the goal of communication is the mutual understanding of the participants.(Habermas 1996, 3.) In contrast to the poststructuralist's view of meaning, Habermas claims that such communicative activity also assumes stability in the meaning of the concepts used in communicative action.(Habermas 1996, 11.) Habermas cites the similarity between Western and Chinese culture on the normative character of "philosophic necessity" as a demonstration that moral questions can be translated across cultures and are thus universalizable.(Habermas 1990, 39.)

Assuming all of these conditions Habermas is ready to make the next claim. The "ideal" by which society, political institutions, and cultural norms can be measured resides within the system of language as those conditions that enhance the ideal of noncoercive discourse with the intended outcome of mutual understanding. Using Kantian language to explain his point, Habermas asserts that the theory of communicative action detranscendentalizes the noumenal, placing its ideal context-transcending logic within the pragmatic presuppositions of speech acts.(Habermas 1996, 19.) Both speaker and listener assume the ideal of mutual understanding as a condition for engaging in communication and this goal carries the weight as a quasi-transcendental normative ideal. Put another way, an analysis of the conditions necessary for mutual understanding allows for the idea of intersubjectivity, making compulsion-free understanding possible.(Habermas 1992, 145.) 


\section{B. Normative Validity}

Having located the ideal of speech within the objective conditions of communication Habermas must now confront another question. Assuming that the conditions for engaging in discourse exist, what criteria are to be used for judgment in the actual conduct of normative discourse? Habermas repeats several times that his model of discourse is not designed to confront the specific content of normative discourse but to outline its conditions.(Habermas 1992, 145-146.) However, Habermas is also aware that to pose a normative structure such as his requires some means of validation. Here Habermas asserts a particular set of assumptions, that while necessary to the achievement of his objective, appear particularly problematic.

Habermas rejects both the late modernism of Weber and the postmodernism of Foucault and Derrida. Weber locates the validity for normative statements within the personal commitments of individual personalities. With a plurality of subjects and possible attitudes toward the world, Weber concluded that normative discourse takes on the character of a war among competing "gods."(Weber in Gerth and Mills, 1946, 152 153.) Foucault and Derrida argue that the origins of normative claims are to be found within the content of culture and history. Lacking any transcendental foundation, normative claims have an arbitrary character and acquire the potential for repression when transformed into institutional practice.

Habermas is forced to confront this critique of modernist universality with a response. He does so with what William Outhwaite calls a "consensus theory of truth."(Outhwaite 1994, 41.) Habermas asserts that normative declarations are assertions of propositional truth claims. All propositions that claim status as truth must be 
proven.(Habermas 1996, 14.) Therefore, claims to normative validity also require demonstration. Normative claims have cognitive meaning and can be treated like other claims to truth.(Habermas 1990, 68.)

To survive the test of validity several requirements must be met. The proposition must be constructed on assumptions that remain unchallenged as part of the environment in the lifeworld. The lifeworld constitutes the background condition for communicative acts.(Habermas 1996,14, 21-22.) Validity, however, comes from consensus. The truth claim must be able to gain the rationally motivated agreement of the entire community.(Habermas 1996, 14.) This requires any normative proposition to "transcend time and space."(Habermas 1992, 139.) It must conform to the principle of universalization. A normative proposition satisfies the conditions of universality if all affected can accept the consequences of it for the satisfaction of everyone's interest.(Habermas 1990, 65.) Thus, a normative proposition is "true" if those affected by it can agree that it is true.

\section{Weakness of Postmetaphysical Validation}

Before moving into the specifics of Habermas's discourse ethics some reflections on truth, validity, and normative universality are in order. For better or worse, Habermas has clearly parted company with the first generation of the Frankfurt School. Instead of offering a critique of instrumental reason, Habermas has universalized the content of reason and reasserted the modernism of Kant over the skepticism of Weber and Lukacs.

Habermas is not content with the Weberian formulation of the ideal type as a subjective model for comparative purposes. Habermas is seeking to ground a non- 
subjective universal truth that can be used for both steering purposes and as a foundation for the generation of solidarity. By locating the normative ideal outside of the subject, Habermas claims to have rewritten the Kantian categorical imperative with deontologized foundation.

Does it work? The answer depends on what assumptions one is willing to concede. To return to Kant's project in a postmetaphysical world Habermas has had to make one addition to the Kantian assumptions of equality and freedom. This is contained in the consensus theory of truth. "Agreement" takes the place of the transcendental content assumed in the Kantian formulation. If one is willing to add this assumption, then Habermas may be palatable thus far. However, a problem still remains. By conjoining normative and empirical claims under the umbrella of cognitive theory Habermas may have created a problem for the consensus theory of truth. It could be argued that in the normative realm, Habermas has confused political legitimacy with propositional truth.

If, however, one is less certain about accepting Habermas's assumptions two alternative criticisms are possible. From a traditional normative perspective that is not "deontologized" Habermas has thrown out the baby with the bath water. In removing the thinking feeling subject from the discourse over context, a context that has now been externalized and objectified, Habermas may be extending the dehumanization of the lifeworld he professes to be against. Habermas may be furthering the project of rationalization looked upon so suspiciously by the very founders of Critical Theory. How can a particular form of political activity be defended if it is not assumed to reinforce a particular construction of the self? 
Looked at from another perspective Habermas's construction may be even more problematic. One of the central assumptions of Habermas is the idea that the identity of concepts and objects that constitute the material elements of discourse remain stable. This is an assumption that not everyone accepts, particularly within a "contextualized" social science. One need not go as far as Derrida and Foucault to raise a question on this point. Once, however, the content of symbolic language becomes tainted by historical analogy the concept of a quasi-transcendent universal is in doubt.

\section{Ethical Proceduralism}

Habermas believes that his articulation of a means for validating normative claims allows for the development of an ethical system that avoids the metaphysical problems associated with early modernism. The consensus theory of truth plays a critical role in returning to the Enlightenment ethic. After incorporating elements of various authors, Habermas returns to Kant for a reformulation of the categorical imperative, now stripped of its metaphysical overtones. A procedure for deriving ethical claims has been created that meets the test of validity and no longer relies on the philosophy of the subject or metaphysical presuppositions for its support. At least, that is Habermas's intent.

\section{A. The Formal Conditions of Normative Discourse}

Habermas's goal is to describe a set of conditions that must be present in order for normative discourse to have validity. These conditions, then, represent the standards by which the conditions of moral discourse are established. Like Kant, Habermas is interested in the form and conditions of normative discourse. Habermas states directly 
that he is not interested in developing a specific content to his moral formulation.(Habermas 1992, 145-146.) Adherence to a "procedure" for the creation of ethical norms assumes the validating role rather than the actual content.

Habermas's "discourse ethics" emerges from several basic assumptions that build on the claims contained in his work on postmetaphysical philosophy. As Habermas puts it, discourse ethics stand or fall on two assumptions: that normative claims to validity have cognitive meaning and can be treated like truth claims and that the justification of norms requires real discourse.(Habermas 1990, 68.) Or as Habermas puts it in Justification and Application, "[a]nyone who seriously engages in argumentation must presuppose... the pragmatic assumption that they allow their "yes" and "no" responses to be influenced solely by the force of the better argument."(Habermas 1993, 31.)

But Habermas really requires more. To these claims several additional assumptions must be noted. First, Habermas assumes that an ideal speech situation is empirically rational, even while denying it presently exits. It cannot be just a "hypothetical, mental exercise"(Habermas 1990, 68.) otherwise it would not carry the cognitive validity that Habermas requires. Second, in contrast to the "warring gods" position of Max Weber and all subjectivist notions of values, Habermas assumes that it is possible to produce an outcome from discourse that is acceptable to all sides. Thus the "principle of universalization" is the foundational premise for the "principle of discourse ethics."(Habermas 1990, 65.) Finally, not only does Habermas assert that the principle of discourse ethics can be used to solve disputes, but that the outcome of this process constitutes the measure of normative validity. The circular dynamic is now complete. 
Habermas admits that this claim has a transcendental character, albeit a weak one.(Habermas 1990, 31.) The principle of discourse ethics states, "[o]nly those norms can claim to be valid that meet (or could meet) with the approval of all affected in their capacity as participants in a practical discourse."(Habermas 1990, 66.) Ignoring for the moment the problems presented by "or could meet," Habermas asserts that normative validity stems not from a connection to a transcendental form of universal morality, but that it emerges from the conditions that allow for real discourse among human beings engaged in the rational conduct of life. The claim is repeated in Between Facts and Norms, where Habermas states that a truth claim is valid if it can gain the rationally motivated agreement of the entire community.(Habermas 1996, 14.) Thus we have the condition where valid normative claims stem from human interaction, but transcend "us" and any local here and now.(Habermas 1996, 14.) Anticipating a challenge on this claim Habermas claims that the method engaged for this demonstration is comparable to "induction."(Habermas 1990, 77.)

Habermas's claim here is not just "comparable" to induction, it is induction. This is clearly demonstrated in Habermas's discussion of the emerging content in ethical systems. The content for ethical discourse has its origins in the composition of culture, tradition, and the "lifeworld." Discourse ethics is only formal. It is a procedure for testing the validity of norms, not a specific assertion of content.(Habermas 1990,103.) Practical discourse relies on content from the outside, where actors feel the need to regulate some issue.(Habermas 1990, 103.) 


\section{B. Problems with Discourse Ethics}

What Habermas hopes to gain is the return to a politics, lost since

Aristotle,(Habermas 1996,1.) that engages practical discourse and avoids a "power centered" politics outlined by the disillusioning voices of sociology. However, Habermas rejects science and behaviorism as a source of universalizable normative prescriptions.(Habermas 1990, 39.) This leaves him with a dilemma. Habermas wants universal norms to emerge from a discursive process. However, the content of these norms have their origins in conditions that are local and specific. Habermas gets around this by asserting only the conditions of discourse constitute the universal.

From the point of view of one who is even mildly skeptical, discourse ethics appears in the following form: as a procedure that legitimates the conversion of inductively drawn generalizations to the status of universals. It does not negate the power of majoritarian discourse, it masks it under the umbrella of universalized ethical procedure. Habermas tries to avoid this with the claim that universal validity can be ascribed only in those instances where the will of all approves or could approve the normative claim. Here the universalization of reason comes into play and its repressive political potential is revealed. The danger of being considered "irrational" negates legitimate opposition to majoritarian proclamations. A majoritarian agenda emerges as the source of content, as Habermas admits that every society needs the unity of a common will.(Habermas 1992, 141.) In this way the community can restore the consensus that Habermas assumes is the natural condition of humanity.(Habermas 1990, 67.)

Problems with Habermas's position are revealed in his anticipation of challenges posed by ethical subjectivism. From that position, exemplified by Weber, value claims 
cannot be validated by external objective criteria. Values constitute internal normative preference on the part of individuals and, as such, are conditioned by history and shaped by the influence of competing values. It is part of the human condition that these values cannot be reconciled, but exist in a state of constant struggle. Consensus is only a temporary truce in the struggle of ideals.

To confront this view Habermas makes two assumptions. The first is that consensus on values can be reached on many matters through a discursive strategy, thus supplanting struggle with "reason." Secondly, the matters that cannot be reconciled through rational discourse should be removed from the arena of debate.(Habermas 1990, 103.) Here Habermas has either made his discourse ethics bland and impractical or utopian and useless to our present circumstance.

In the end, the discourse ethics that Habermas proposes is both illusory and contradictory. What has really been solved? In matters of real dispute, the inability to provide content appears as a severe weakness. In this regard, Habermas's reformulation of the Kantian categorical imperative(Habermas 1990, 67.) does not solve the problem of content also found in Kant. Substituting the consensus view of truth for Kant's transcendental reason only further politicizes philosophic inquiry, substituting a majoritarian notion of political legitimacy for philosophic validity.

There is also something familiar about the mechanism by which Habermas suggests we validate norms. If we are using "something like" induction to reach the universal normative claims and, as Habermas concedes, the world is a totality of facts(Habermas 1996, 14.) that might require us to revisit normative claims when confronted with new information(Habermas 1990, 86.), is it not contradictory to suggest 
that anything universal has come out of this process at all? To assert the historical nature of the content is to strip discourse ethics of any practical character for settling disputes. Certainly the prescriptive outcomes cannot claim universal validity. Even the universal character of the proceduralist ethic is suspect. In the final analysis, Habermas's discourse ethic reinforces the mode of existence to which Habermas has already committed. It does not "prove" the universal character of ethics.

Anticipating a challenge to his discourse ethics, Habermas employs an argument from Karl-Otto Apel. Apel claims that any challenge to the presuppositions of the universal principles of argumentation actually engages those principles in the process of negation. In this way one can be skeptical of the skeptic's claims. However, the skeptic can respond to such a claim by arguing that the assertion "no universal validity can be established to any normative claim" takes the form of a metatheoretical proposition that denies the possibility of engaging in "rational, universal, ethical" discourse. To the skeptic, rational universal discourse in the area of ethics manifests the same internal contradiction as the discussion of a square circle.

\section{Political Discourse and the Law}

The political agenda that underlies Habermas's project can be simply stated. With the coming of the postmetaphysical age, the foundation for democratic practice and the protection of political rights has disintegrated.(Habermas 1995, 14.) This disintegration has been enhanced by systems theory and empiricism, two approaches that have effectively eliminated the normative consideration of social solidarity. 
To Habermas, the law has a particularly important role to play in the reconstitution of the social solidarity. Only a conception of law that maintains its integrating function can overcome the disintegrating effects of a disillusioning sociology. When natural law lost its universal character in the Nineteenth Century, the Aristotelian notion of a societal ethos gave way to a subjectivist interpretation of the normative.(Habermas 1996, 96) When the sacred character of culture dissipated, the legal system was left to perform the integrating function.(Habermas 1996, 98-99.) Only discourse ethics applied to the consideration of law can end the increasing separation between political theory and legal theory.(Habermas 1996, 6.)

\section{A. The Reconstruction of the Universal as a Means to Salvage Solidarity}

Habermas's statement in the introduction to Between Facts and Norms should be take quite literally. The resource that he sees endangered within the current conception of the legal order is social solidarity.(Habermas 1996, xlii.) If this is the case, then the objective of Habermas's political project comes into focus. He seeks to create a new foundation for a universalized conception of legal order that retains both the postmetaphysical epistemology and a defense of democratic practice. The task is complicated by the fact, as Habermas admits, that the world is increasingly plural and complex.(Habermas 1996, 25.)

Habermas admits that increasing social complexity can bring about a decline in shared lifeworld assumptions, generating political instability.(Habermas 1996, 25.) But Habermas has already set the stage for dealing with this problem in Postmetaphysical Thinking and Moral Consciousness and Communicative Action. The discursive goal of 
"mutual understanding" suggested in Postmetaphysical Thinking gives way to the political goal of achieving consensus. This displacement allows for the implementation of communicative reason, an external prerequisite for validity within the political realm.(Habermas 1996, 3-5.) The assertion of universal reason, coupled with the idea that consensus is the measure of normative validity, allows for the reconstruction of political legitimacy within a framework of participatory democracy. This situation, claims Habermas, can recapture the ideal of solidarity and not succumb to the danger of repression suggested by systems theory and poststructuralism.(Habermas 1992,140.)

Solidarity reemerges within Habermas's scheme not from the creation of a common universalized content of morality, but through the recognition of a common set of procedures for normative discourse. In communicative action, the speaker and hearer attempt to negotiate and harmonize their respective plans through mutual understanding.(Habermas 1996, 18.) Every action coordinated without violence represents a demonstration of the activity of mutual understanding.(Habermas 1996,17.)

The discursive process joins reason and will together, as language oriented to mutual understanding. The outcome of this process should lead to a position to which all can agree.(Habermas 1996, 103.) The norms that are represented in the outcomes of this practice are only valid if a such an agreement can be found.(Habermas 1996, 107.)

What happens where there are disagreements? Here Habermas may have established an unrealistic response to this very real question. The standard for normative validity is that everyone effected must, in principle, be able to agree to the proposed norm. Admitting that there is a possibility for disagreement over normative claims Habermas suggests three choices among outcomes; repairing the consensus, ignoring the 
area of disagreement, or withdrawing from public discourse.(Habermas 1996, 21.) Since withdrawal is associated with the irrationalism, madness, or isolation he attributes to the postmodern attitude,(Habermas 1992, 145.) Habermas is left with only two possibilities.

To Habermas, consensus is difficult given the fact that the plurality of modern culture has eroded the background consensus in the lifeworld.(Habermas 1996, 25.) Since the conditions for consensus are found in the content of traditions and socialized identities within the lifeworld(Habermas 1996, 80.) this would seem to present an insurmountable obstacle.

But Habermas is not willing accept this conclusion, one that he associates with systems theory.(Habermas 1996, 330-341.) In its place he offers two responses, one ideal and the other practical. The ideal response is contained in the discussion of the teleology of communication. Habermas assumes that communication occurs in order to reach understanding. Understanding is a goal within normative discussions as well. Ideally, when a disagreement occurs each side must learn from the other, bringing about a convergence of ideas, not a subservience of one idea to the other.(Habermas 1992, 138.) Habermas gives an indication of how this is achieved in Between Facts and Norms, suggesting that if there is an ethical disagreement neutral dialogue requires transition of the discourse to a higher level of abstraction where participants examine what lies in the equal interests of all.(Habermas 1996, 311.) Ideally, in the discursive process reason and will are brought together as language oriented to mutual understanding that can lead to a position that all can accept without coercion.(Habermas 1996, 103.)

The practical side of this formula is the art of political bargaining through the legislative process.(Habermas 1996, 287.) Consensus is not something that is found, but 
something that is built through public discourse. Majorities emerge through persuasion. Legitimate consensus can emerge, therefore, where the conditions for communicative reason are present. Here the law plays a critical role in securing the conditions for communicative reason and protecting the space for true political discourse.

\section{B. Democracy, the Law, and the Administration of Power}

One of the problems Habermas identifies with systems theory is that it presents a view of social life as a set of independent subsystems that are incapable of cross-system communication.(Habermas 1996, 335-341.) To put this in the language of systems theory, there is no meta-language that can cut across the subsystems as each contains its own grammar and its own mechanism for validating truth claims. Having demonstrated to his own satisfaction that this is not the condition of social life, Habermas rejects the political implications of Niklas Luhmann's systems theory as well as the political claims of the postmoderns..

Habermas wants to return to the Aristotelian notion of politics as the master science. The political system is one among many subsystems, but it has a unique role to play. The "political" has the specific function of communicating with the other subsystems.(Habermas 1996, 302.) Thus, the integration function of politics takes on a more general role. It is not the individual alone that is the subject of the integrating effects of political discourse, but the other functional subsystems as well. This integrating function is carried out by the law.(Habermas 1996, 17.)

The integrating function of the law, which means it cannot be separated from the source of its legitimacy in the lifeworld, necessitates a connection between the legitimacy 
of legal codes and democratic practice.(Habermas 1996, 295.) Only democratic procedures can legitimate the law.(Habermas 1995, 16.) The law is bound to the lifeworld through ordinary language below the system of legal codes.(Habermas 1996, 55.) It is the law that constitutes the transforming mechanism between the normative foundations represented in the lifeworld and the system of administrative power.(Habermas 1996, 81.) To claim legitimacy, therefore, the law must represent the general will and this can only occur through open democratic discourse.

Thus, Habermas claims that human rights are secured as part of the conditions necessary for the public use of communicative freedom.(Habermas 1995, 16.) Public autonomy and private autonomy presuppose each other.(Habermas 1995, 17.) As Habermas puts it, human rights and popular sovereignty still constitute the sole ideas that can justify modern law in the absence of metaphysics.(Habermas 1996, 99.)

Grounding morality outside of metaphysics allows Habermas to return to a reconstructed version of the Kantian formulation, suggesting that legal and moral rules, while different, should complement one another.(Habermas 1996, 105.) In place of the philosophy of the subject Habermas has grounded the foundational support for his moral and political order in the conditions of communication. As Habermas puts it, "[t]he 'self' of the self-organizing legal community disappears in the subjectless forms of communications that regulate the flow of discursive opinion- and will-formation in such a way that their fallible results enjoy the presumption of being reasonable."(Habermas 1996, 301.) To put it simply, the outcome of the discursive practice is considered to be legitimate because the form of discourse followed a notion of popular sovereignty located in the conditions for discourse itself. Thus, even while Habermas is mildly critical of 
Robert Dahl, he finds Dahl's proceduralist notion of democracy an important addition to democratic theory.(Habermas 1996, 315-318.)

Democratic procedures also legitimate the coercive function of law. Legitimate coercion must be linked to the self-legislation of citizens.(Habermas 1996, 33.) The law cannot be arbitrary without severing its link to the lifeworld and losing its integrating function.(Habermas 1996, 38.) The less that the conditions for open discourse are found the more force will be required by the administrative system of power to maintain order.(Habermas 1996, 30.)

Therefore, Habermas claims that the level of open discourse is the measure of democracy in a society.(Habermas 1996, 303.) The constitutional state and the welfare state can both be constructed without democracy.(Habermas 1996, 78.) The construction of a true constitutional order (Rechtsstaat) is designed to protect the conditions of open discourse. Disruptions to open discourse, Habermas claims, can come from the economic and administrative subsystems.(Habermas 1996, 56.)

The law lost its connection to normativity when the idea of natural law gave way to economic law.(Habermas 1996, 45.) This allowed the penetration of values other than solidarity into the political discourse. Today administrative power has become increasingly independent, short circuiting democratic procedures and legitimating its legal codes simply by enacting them.(Habermas 1996, 329.) Our current political crisis is deepened by the unequal distribution of economic power that has diminished the potential to make effective use of the equal distribution of legal power.(Habermas 1995, 18.) Habermas concludes that the normative character of the law can only be secured with a more just distribution of socially produced wealth.(Habermas 1995, 18.) 
Our current social, political, and moral problems can only be overcome through a return to a form of politics that embraces the normative character of political discourse and returns the state to the apex of political life.(Habermas 1992,140.) Solidarity must be able to hold its own against the influences of money and power.(Habermas 1996, 299.) An open field for communication must be maintained if the acts of collective will formation are to be considered legitimate. The modernist ideal of unity, human rights, and democratic practice represent sound, normatively defensible ideals that have yet to be realized.

\section{Teleological Ethics and Political Practice}

With the publication of Between Facts and Norms Habermas has closed the circle. A non-metaphysical defense of democracy and the legal order has been constructed based on the premises of the discourse ethics. To Habermas this achievement represents a return to the Kantian ethical system which has now been stripped of an ontology of the subject.

But what has Habermas really done with the return to Kant? Has Habermas really removed the subject from the consideration of ethics? At least two challenges to Habermas can be made. It was Max Weber's contention that procedures and content cannot be so neatly separated. As Weber put it, every political system must be evaluated according to the type of person it promotes.(Weber 1949, 27.) From the perspective of the poststructuralists, an ethical commitment implicitly defends a particular structure of the subject by making the realization of a particular normative pattern of life possible. Therefore, from either a Weberian or a poststructuralist perspective, Habermas has not 
proven the universality of reason and subjectivity, he has assumed them in order to operationalize his project. Only then does the rest of the argument logically follow.

Even if one accepts Habermas's claim that he has removed subjectivity from the centerpiece of his system, the question of whether or not a metaphysical turn has be made remains open. To put it simply, in attempting to remove the subject, Habermas has put increasing weight on a teleological conception of democracy's historical development as an indication of the validity of his discourse ethics. Communicative action is a concept by which society can be analyzed, but it cannot maintain an objective status unless asserted as a teleological objective. Despite Habermas's denial(Habermas 1992, 142.), one is either forced to return to a defense of the subject (Kant) or a philosophy of history (Hegel). He has, therefore, not constructed a postmetaphysical defense of modernity, he has simply shifted the emphasis from ontology to teleology.

Even if we assume that he has succeeded in constructing a non-metaphysical defense of democratic practice, in the final analysis what would we have? If Habermas has reconstructed the Kantian categorical imperative of what use is it? In the Metaphysical Foundation of Morals, after Kant provides the reader with the justification for the categorical imperative, he then tries to apply it. The results are so encumbered with additional assumptions, predisposed ethical norms and commitments, and possible alternative responses, such that the intent of the categorical imperative is rendered useless in application.(Kant 1977, 170-172.) This conclusion was reached by John Stuart Mill in his writings on utilitarianism,(Mill 1963, 246.) and was one of Nietzsche's criticisms of Kant.(See Nietzsche 1973, 23. and Nietzsche 1989, 65.) 
The same criticism is valid for Habermas's reformulation. Testing a universalist assumption by seeking consensus will either result in doctrines that are so vague that they are useless in the conduct of real decision making or generate paralysis in actual application. The door is left open with the assertion that legitimacy stems from moral conclusion to which all could agree, but then the political struggle is likely to emerge around who sets the parameters as to the rational content of "could." In the end, simple majoritarianism is likely to be the outcome when applied in practice. From a classical liberal perspective, Habermas's neo-Aristotelian project would be particularly dangerous as discourse ethic erodes the barrier between the public and the private.

In the final analysis the application of discourse ethics also does not confront the distortions of communication brought about by wealth and power, but buries them under a utopian formulation. Ethics based on universal consensus ignores the necessity of making decisions that do not offer the possibility of consensus. It ignores the real fundamental differences in interests and commitments that make politics an arena of conflict as well as cooperation. One does not have to adopt the late modernism of Weber or the postmodernism of Derrida and Foucault to understand that real differences about fundamental issues lie at the core of political life.

\section{Conclusion: The Politics of Stability}

Read strategically, the defense of democracy and other Enlightenment ideals do not emerge as demonstrated "truths" from Habermas's analysis, but serve as premises for the exploration of political possibilities. An observation of Kant made by Nietzsche can also be applied to Habermas. In seeking to realize what he desired, Nietzsche claims 
Kant found himself inventing the conditions that made it possible.(Nietzsche 1973, 23.) From this perspective, the fortification of modernity is a premise that underlies Habermas's project, out of which he develops the consensus theory of truth, discourse ethics, and the formal structure of democratic politics.

Returning to Kant, whether as postmetaphysics or neometaphysics, represents a fundamental break for critical theory (if one can even still call Habermas a "critical theorist" as at all). Habermas has given up the idea that modernity itself may hold the seeds of human alienation and disintegration. The critical edge of Weber and Freud as developed by Lukacs, Adorno, and Horkheimer has now disappeared. The power of Weber's notion of instrumental reason at the core of the Frankfurt School has given way to the universalization of reason as the engine of modern democracy. The liberating potential of Freudian psychoanalysis has been supplanted by the bland outline of democratic procedures found in Robert Dahl.

Habermas clearly does not want to raise any questions about the commitment to modernity. However, this ignores the sources of estrangement and discord within modernity itself. The problems presented by modernity are greater than the problems raised by capitalism and the administrative state. The process of objectification is embedded within modernist epistemology, whether used within the economic or administrative systems.

Habermas's concern with democracy and solidarity are consistent with the agenda of both Marxism and critical theory. But what kind of Marx is it? There are no references to the objectifying character of the division of labor within modern industrial production. To Habermas, the only problem in the modern political economy appears as 
the potential for "illegitimate" political influence asserted by wealth and power. Habermas has attached himself to modernity's promises while refusing to recognize modernity's underlying conditions remain part of the problem.

By refusing to identify modernity with any of our contemporary problems Habermas has demonstrated a conservative turn in his thinking. Consensus produces legitimacy. Legitimacy maintains stability. System stability, whether called "solidarity" or just simply "order," have taken priority over the idea of liberation. The law has a particular role to play as it not only becomes an agent of social solidarity but also ..."can relieve the morally judging and acting person of the considerable cognitive, motivational, and organizational demands of a morality based entirely on individual conscience."(Habermas 1995, 15.) This is not a liberating prospect.

Like Socrates in The Republic Habermas admits that no society will achieve his pure model of a communicative politics.(Habermas 1996, 326.) The value of Habermas's project, then, can be seen in its role as a measure of the discursive space made available in political regimes.(Habermas 1996, 5.) However, it may also be illustrative to take note of another statement by Socrates. In Book Three of The Republic Socrates states that at times a lover of the state might need to construct a "fiction" in defense of the social order, as a doctor uses medicine against a disease.(Plato 1955, 86.) Can such a charge be brought against Habermas? Could it be that out of a desire to overcome a perceived disease of disillusionment and disintegration in the West Habermas has constructed this model of ethical and political life? Such a question is not easily answered. However, the administration of any medicine first requires a correct diagnosis of the condition. A lack of "order" does not seem to be Western societys' problem at this point in history. 


\section{References}

Fleming, Marie. 1996. "Working in the Philosophical Discourse of Modernity," Philosophy Today 40:1, pp. 169-178.

Foster, Roger. 1999. "Strategies of Justice: The Project of Philosophy in Lyotard and Habermas." Philosophy and Social Criticism, 25:2, pp. 87-113.

Habermas, Jürgen. 1983. "Modernity: an Incomplete Project," The Anti-Aesthetic. editor, Hal Foster. Washington: Bay Press.

Habermas, Jürgen. 1984. The Theory of Communicative Action. Volume I. Boston: Beacon.

Habermas, Jürgen. 1990. Moral Consciousness and Communicative Action. Cambridge: MIT Press.

Habermas, Jürgen. 1992. Postmetaphysical Thinking. Cambridge: MIT Press.

Habermas, Jürgen. 1993. Justification and Application. Cambridge: MIT Press.

Habermas, Jürgen. 1995. "On the Internal Relation Between the Rule of Law and Democracy," European Journal of Philosophy, 3:1

Habermas, Jürgen. 1996. Between Facts and Norms. Cambridge: MIT Press.

Horowitz, Asher. 1998. "Like a Tangled Mobile: Reason and Reification in the Quasidialectical Theory of Jürgen Habermas.” Philosophy and Social Criticism, 24:1, pp. 1-23.

Hume, David. 1962. On Human Nature and the Understanding. New York: Macmillan

Kant, Immanuel. 1965. The Metaphysical Elements of Justice. Indianapolis: BobbsMerrill.

Kant, Immanuel. 1977. The Philosophy of Kant. editor, Carl J. Friedrich. New York: Modern Library

Kaufman, Cynthia. 1999. "The Unforced Force of the More Familiar Argument: A Critique of Habermas' Theory of Communicative Rationality." Philosophy Today, 43:4 pp. 348-360.

Locke, John. 1961. An Essay Concerning Human Understanding. London: J. W. Yolton

Mill, John Stuart. 1963. Six Great Humanistic Essays of John Stuart Mill. New York: Washington Square Press. 
Nietzsche, Friedrich. 1973. Beyond Good and Evil. London: Penguin.

Nietzsche, Friedrich. 1989. On the Genealogy of Morals and Ecce Homo. New York:

Vintage.

Outhwaite, William. 1994. Habermas: A Critical Introduction. Stanford: Stanford University Press.

Plato. 1955. Republic. New York: Vintage

Weber, Max. 1946. From Max Weber. editors Gerth and Mills, Oxford: Oxford University Press.

Weber, Max. 1949. Methodology of the Social Sciences. New York: Free Press.

Whitton, Brian J. 1992. "Universal Pragmatics and the Formation of Western Civilization: A Critique of Habermas's Theory of Human Moral Evolution." History and Theory, 31:3, pp. 299-313. 